\title{
CULTURE ET COMMUNICATION
}

\author{
Marc Lits ${ }^{1}$
}

Les sciences de l'information et de la communication se sont progressivement constituées en discipline (ou en interdisipline, peu importe ici) en prenant leurs référents théoriques et méthodologiques dans des domaines voisins, auprès de sciences humaines bien installées comme la sociologie, la philosophie ou les sciences politiques, mais aussi dans des domaines plus récemment explorés, comme la sémiotique, et plus récemment les cultural studies. On sait que ce champ d'exploration des pratiques culturelles et sociales a émergé en GrandeBretagne grâce aux travaux fondateurs de Richard Hoggart et de Stuart Hall, popularisés par les recherches menées au Centre of Contemporary Cultural Studies de Birmingham dès 1964. Mais si les cultural studies se sont développées dans le monde anglo-saxon, et ont connu un succès grandissant aux Etats-Unis, elles on rencontré de grandes difficultés à s'implanter dans le champ francophone. Dominique Pasquier a montré, dans un numéro de la revue Hermès, combien les positions sociologiques de Pierre Bourdieu, qui ont dominé cette discipline pendant de longues années, ont empêché ces lectures alternatives de se développer dans l'espace francophone ${ }^{2}$. Dans ce même numéro, l'article suivant était dû à la plume de Jan Baetens, et s'intitulait « La culture popu-

1 Marc Lits est professeur au Département de communication de l'UCL, directeur des revues Recherches en communication et Médiatiques, et membre de la rédaction en chef de la revue Hermès.

2 Dominique Pasquier, «La “culture populaire” à l'épreuve des débats sociologiques », Hermès, $\mathrm{n}^{\circ}$ 42, 2005, pp. 60-69.

Recherches en communication, $\mathrm{n}^{\circ} 31$ (2009). 
laire n'existe pas, ou les ambiguïtés des cultural studies $»^{1}$. L'auteur y présentait les apports de ce courant pour comprendre les productions culturelles de masse, tout en montrant les limites de ces positions souvent très marquées idéologiquement.

Peu de temps auparavant, Armand Mattelart et Erik Neveu avaient déjà publié une première Introduction aux cultural studies ${ }^{2}$ et des sociologues comme Eric Maigret ou Eric Macé allaient prolonger ce mouvement en rééditant, entre autres, les textes fondateurs de ce courant, dans des traductions françaises ${ }^{3}$. Mais il est significatif que ce soit un chercheur non francophone qui ait été un des premiers à introduire en Europe francophone les débats relatifs aux apports des cultural studies à la recherche en communication. Jan Baetens, comme d'autres chercheurs belges, est en effet au croisement des cultures francophones (par sa formation initiale en littérature française) et anglo-saxonnes (puisque les universités flamandes ont toujours été plus réactives aux auteurs publiant en anglais). Son parcours pluridisciplinaire, reposant sur une solide connaissance des approches littéraires, linguistiques, sémiologiques, anthropologiques l'a amené à créer un département de culturele studies à la KUL ${ }^{4}$ (Leuven), qui est rapidement devenu un des moteurs européens de la recherche dans ce domaine.

Très naturellement, Jan Baetens a dialogué avec les chercheurs en communication, parce qu'il s'intéresse aux mêmes objets : la photographie, la bande dessinée, les graphic novels, et qu'il s'inspire de méthodologies similaires : la sémiotique peircienne, la sémiologie d'inspiration structurale, les études de réception... Et tout aussi naturellement, puisque la KUL et l'UCL sont des universités sœurs, son département et notre département de communication sont associés depuis de longues années. Echange d'étudiants, organisation commune de colloques (sur la novellisation ${ }^{5}$ ou la photographie ${ }^{6}$, entre autres), recherches et publi-

1 Jan Baetens, Hermès, $\mathrm{n}^{\circ}$ 42, 2005, pp. 70-77.

2 Armand Mattelart et Erik Neveu, Introduction aux cultural studies, Paris, La découverte, coll. "Repères", $\mathrm{n}^{\circ}$ 363, 2003.

3 Eric Maigret, Eric Macé, Penser les médiacultures, Paris, Armand Colin, coll. "Médiacultures", 2005 ; Hervé Glevarec, Éric Macé, Éric Maigret (éd.), Cultural Studies. Anthologie, Paris, Armand Colin, coll. "Médiacultures", 2008.

4 Le programme est consultable à l'adresse http://www2.arts.kuleuven.be/cs/.

5 Les actes en ont été publiés dans J. Baetens et M. Lits (eds), La novellisation/ Novelization. Du film au livre. From film to novel, Leuven, Leuven University Press, coll. "Symbolae - Series D Literaria", vol. 17, 2004.

6 Les actes en ont été publiés dans le $\mathrm{n}^{\circ} 27$ de Recherches en communication, 
cations collectives : ce sont autant d'activités qui ont permis de créer des partenariats fructueux, mais surtout de développer une réflexion conjointe sur les intérêts d'un croisement des recherches en communication et en études culturelles (pour reprendre l'expression, délibérément en français, de l'intitulé d'un cours créé au département de communication en 2007).

Dès lors, il a semblé évident pour notre département de proposer, en étroite collaboration avec les Facultés universitaires catholiques de Mons (FUCaM) le nom de Jan Baetens pour occuper une des chaires annuelles les plus prestigieuses en Belgique, la chaire Francqui. Grâce à ce mécénat, Jan Baetens a pu dispenser un cycle de six conférences, à Mons et à Louvain-la-Neuve, au printemps 2008, qui ont donné lieu à des débats féconds, qu'il nous a semblé opportun de prolonger dans ce numéro.

Nous reproduisons donc dans ce dossier les six conférences, remaniées par leur auteur, qui abordent six aspects très différents interrogés à la fois par les études culturelles et par les scieces de l'information et de la communication. Le premier article propose une autre définition de la culture, fondée sur les études culturelles, pour lesquelles la notion de culture est plus qu'un corpus d'objets, d'œuvres ou d'événements : c'est avant tout une pratique, voire une façon de vivre. L'article présente quelques aspects de cette définition et de cette approche, illustrés par des exemples tirés de la photographie et de la bande dessinée.

Le deuxième article est consacré à la photographie documentaire. Parler de photographie documentaire paraît un pléonasme, mais les choses se compliquent dès qu'on sépare les objets et les usages. On s’y intéresse à quelques usages documentaires de la photographie (archives du XIXe siècle, presse illustrée du XXe siècle), puis à la distinction entre photographie documentaire et "style documentaire", avant d'analyser les problèmes qui se posent à ce type de photographie, forme et usage confondus, dans le monde contemporain.

Le troisième article est consacré au concept discuté de remédiation. Si la notion de média joue un rôle clé dans la culture, c'est aussi à cause de la mobilité permanente qui caractérise l'univers des médias. Dû à J. D. Bolter et R. Grusin, qui relisent les théories de McLuhan à cet égard, le concept de re-médiation désigne la substitution d'un média (nouveau) à un autre (ancien). Ce concept est mis en discussion, notam-

«Photographie et communication », 2007. 
ment à l'aide d'une relecture du manifeste de McLuhan, The Medium Is the Message, et d'une réflexion plus générale sur le "tournant visuel" de la culture.

Le quatrième article propose un regard méthodologique sur une approche peu connue : l'approche SCOT (pour "construction sociale de la technologie", "Social Construction Of Technology"), qui s'intéresse essentiellement aux bases culturelles des mutations technologiques. C'est une discipline proche de la sociologie des sciences qui n'est pas sans rapport avec les études culturelles. Jan Baetens présente ici les grandes lignes méthodologiques de cette approche, illustrée dans le domaine anglo-saxon par des auteurs comme T. Pynch et W. Bijker et en France, d'une certaine façon, par B. Latour.

Dans le cinquième article, Jan Baetens revient sur un de ses objets de prédilection, emblématique des développements de la culture de masse : la novellisation. Autant tout le monde connaît le phénomène de l'adaptation cinématographique d'œuvres littéraires, autant le phénomène inverse, la réécriture de films sous forme de romans, reste une pratique confidentielle (bien que capitale du point de vue culturel). Jan Baetens décrit l'historique de ce genre en France, avant de commenter un exemple classique (Les Vacances de M. Hulot) qui démontre que la novellisation est une forme culturelle d'une richesse et d'une complexité insoupçonnées ${ }^{1}$.

Enfin, le dernier article tourne autour de la mémoire culturelle. Définir la culture en termes de transmission et de mémoire culturelles, c'est poser la question de la formation, du maintien, de l'activation d'un certain patrimoine, de certaines formes d'héritage plutôt que de telles autres. Cette problématique est examinée de trois points de vue : l'objet (que faut-il retenir ?), les institutions (qui a le droit de décider ce que l'on retient ?) et les infrastructures technologiques (par quels moyens va-t-on faire durer la mémoire ?).

Le lecteur, même distrait, aura tôt fait de remarquer que ce dossier ne contient pas six articles, mais douze. Il nous a en effet semblé intéressant de continuer les échanges tenus durant les séminaires, en demandant à six chercheurs issus du champ de la communication de prolonger chacun des articles de Jan Baetens. Certains réagissent par quelques gloses en interaction, d'autres rebondissent sur un des aspects développés pour l'appliquer à un objet médiatique, d'autres encore proposent

1 Depuis lors, Jan Baetens a développé ses recherches à ce sujet dans son livre $L a$ novellisation. Du film au roman, Bruxelles-Paris, Les Impressions nouvelles, 2008. 
une discussion critique des concepts développés par l'auteur. Chacun avait carte blanche pour entrer en résonance, comme il l'entendait, avec un des six textes de départ. Ce qui nous donne un remarquable exemple de disputatio, destiné à nourrir nos acquis en analyse de la culture, des médias, de la communication. Andrea Catellani, Sandro Faes, Axel Gryspeerdt, Sébastien Fevry, Alain Reyniers et Sarah Sepulchre se sont prêtés au jeu. Pour notre plus grand plaisir, pour le plaisir aussi des lecteurs, nous l'espérons. 